\title{
The Construction of 233 Integrated Experimental Teaching System in the Major of Economics and Management
}

\author{
Jiange Cong ${ }^{\mathrm{a}}$, Bin Li ${ }^{\mathrm{b}}$ \\ Shandong University of Finance and Economics, Jinan 250014 \\ aJgcong3282@sina.com, bibincar@126.com
}

Keywords: Economics and management, Integration, Experimental teaching, System

\begin{abstract}
There are many problems in the experimental teaching in the major of economics and management, such as lacking systematic design with many education and teaching links including theoretical teaching, scientific research, social practice, innovation and entrepreneurship, failing to deeply understand and effectively implement the student standard, forming the low degree of integration between experimental teaching technology and education teaching, constructing the information lonely island of experimental teaching and etc. Guided by the interconnected thinking, computational thinking and big data thinking, Shandong University of Finance and Economics sets up the experimental teaching ideas of extension, docking/matchmaking and integration, designs the reform plan of 233 experimental teaching system including the extension in two directions, three connections and three integrations. It also promotes the transformation from the experimental teaching in the economics and management major to the intelligent experiment by optimizing contents, improving methods, integrating resources and making innovations in modes. The integrated experimental teaching reform characterized by the all-dimensional and multi-level pattern can not only effectively cultivate students' ability of learning, practice, innovation and entrepreneurship but also explore the feasible way to achieve the sustainable development of experimental teaching depth in economics and management major.
\end{abstract}

\section{Introduction}

With the multiple attributes including nature, technology and humanity and the internal functional advantage of cultivating the practical ability, experimental teaching is one of the important ways to develop the ability of innovation and entrepreneurship of the undergraduates/college students today and the indispensible important component in the process of cultivating high-quality and innovative talents. The experimental teaching in the field of economics and management has made rapid development in the past 20 years and has undergone the times of manual analog, digitization, networking and intelligence. It has grown from scratch. In the development process, it has been transformed from a single course into an integrated/comprehensive course and has gradually formed the certain teaching system (the systematic course group) from the individual course(course unit/structure). However, after resolving the problem about the existence foundation of rationality and realizing the rapid development, the experimental teaching in economics and management major is still faced with many problems including excessive demonstration and verification experiments, students' lack of self-study and deep learning, the transformation from experimental teaching into information lonely island and the lack of sharing and interconnection between universities and other education and teaching links. In order to promote the intensive improvement of the quality of cultivating the talents specializing in finance and economics, Shandong University of Finance and Economics implements the all-dimensional and deep-level reform and positively explores the way to realize the sustainable development of experimental teaching depth in the economics and management major according to the thoughts of integrated system. 


\section{The Rational Thinking on the Systematic Construction of the Integrated Experimental Teaching System}

\subsection{Objective: To promote the fuzzy boundary of the internal respective supply subsystems of education among universities and the achievement of the return of undergraduate teaching.}

The boundless education theory not only advocates that education should break through the limit of time and space, but also makes an appeal to universities to promote the information sharing, integration and innovation of educational resources to the most degree. The structual and geographical boundaries of the traditional ways of higher education are broken down. They are able to be penetrated, or they even have no boundary. Extending the connotation of no boundary theory, this paper thinks that the experimental teaching can achieve the mutual embeddedness and permeation with the respective internal supply subjects of educational resources including theoretical teaching, scientific research, social practice, innovation and entrepreneurship in time and space and finally reaches the equilibrium of the fuzzy boundary among the various subsystems of education and teaching by virtue of the emerging teaching technology, methods and means. The 2.0 era of Educational Information in China pushes the application of information technology and analytic technology of big data and improves the chances for realizing the ideal education of teaching students in accordance with different aptitudes in the big data era. It is the imitation and reduction of the personalized education mode of mentorship and becomes more precise and profound than the ancient ideal education. In addition, all of the above is based on the perspective of experimental teaching and it can strongly echo the manifesto of returning to common sense, duty, original aspiration and dream.

\subsection{Direction: Realize the integrated construction of experimental teaching system by the coordinated development and mutual promotion.}

On the one hand, experimental teaching cannot continue deepening the innovative reform and play a greater role in cultivating the talents in universities without the assistance of the integrated matching support of other teaching subsystems. For example, a series of top-level system designs of education and teaching including school talent traning program, the overall framework of practical teaching system and the reward for undergraduate's technological innovation in extracurricular directly determines the system design of experimental teaching courses. On the other hand, the higher education in China is constantly expanding and deepening from general /liberal education, professional education, quality education to the education of innovation and entrepreneurship. Because of the internal attribute of its multiple educational functions, experimental teaching can resonate and relate with various educational reforms. It is easy to find that the experimental teaching can always find the appropriate starting point to combine and connect with every higher education supply modes dicussed above. We think that experimental teaching is an important organic component embedded in the comprehensive reform of undergraduate education and teaching and there is a mutual promoting and symbiotic relationship between it and other education and teaching links.

\subsection{Perspective: What is experimental teaching in the undergraduate education and teaching? Is it the explicit learning or implicit learning?}

The answer of this question is mainly directed to the dialectic relationship between theoretical teaching and experimental teaching. In addition, they are the two subsystems of the total teaching activity, so it is necessary to control the relationship between them, organically integrate with each other and make the teaching activity as a whole constituted by their mutual influence and mutual promotion. With the gradual development and maturity of mobile internet, big data, cloud computing, $\mathrm{AI}$ and other information technologies, the boundary between formal learning and informal learning and the boundary between class teaching and experimental teaching will become more blurred, and the construction of thr integrated experimental teaching system will be endowed with the new connotation of the times. Following the stage regularity of the development of things, the 
experimental teaching is gradually entering upon the stage of steady development and it will finally integrate with the theoretical teaching to provide service for the cultivation of college talents, scientific research, social service, and cultural inheritance and etc. The theoretical teaching and experimental teaching interwine with each other and they are inseperable. There is no deliberate boundary between them. The practitioner of experimental teaching should break up the chain of the boundary between them and reexamine the present and future of experimental teaching from the overall perspective of undergraduate education and teaching rather than considering the experimental teaching too briefly.

\section{The measure of the systematic construction of 233 integrated experimental teaching system}

\subsection{The Extension in Two Directions.}

Raise the proportion of the case teaching links and dependent experimental teaching links in the system of the basic and professional theory courses. Focus on the introduction of the new teaching forms including the micro experiment embedded teaching, experimental teaching case and cloud experimental teaching. The micro experiments in economics and management means that teachers and students use the mobile terminal equipment (such as mobile phones, PCs and others) to break through the limit of time and space and launch a short-term experimental teaching on the theoretical teaching site according to the syllabus in the class teaching of economics and management.

Construct the experimental teaching links characterized by the interaction of the extracurricular practice. Expand the ways of social practice and investigation and the establishment of the open experimental teaching projects based on actual problems and promote the integration between enterprise, university, research and application by relying on the on-campus experimental teaching platform. For example, students in the college of management science and engineering participate in professor Zhang's research subject called The Research and Application of the internal auditing mode and process optimization in the tobacco commercial enterprises based on the information integration. They construct the internal auditing and performance assessment mode in tobacco commercial enterprises based on the guidance of process efficiency and risk control, effectively deal with the financial risks in tobacco commercial enterprises, bring the direct benefits to enterprises and improve the methods of scientific research and the ability of solving the practical problems.

\subsection{Three Connections: The Integrated Optimization of Experimental Content, Method, Resource and Other Elements}

\subsubsection{The interconnection between the experimental teaching resources in different subjects.}

According to the thought of the great economics and management, long process, large span, high fidelity and crossing integration between different subjects, the university carries out the functional deconstruction and modularity combination of the experimental teaching contents in the subjects of economics and management. Relying on the system design of compulsory teaching and elective teaching and the central open operating mode, it also constructs the campus simulation business operating environment with characteristic of the crossing integration between subjects and plans the design of enterprise operating module(the resource management experiment of the enterprise internal factors of production), business service module(the resource management experiment of the factors of production among enterprises), public service module (the resource management experiment of the enterprise external factors of production), decision module of innovation and entrepreneurship (the resource deci management experiment of the enterprise external factors of production).

\subsubsection{The matching connection between experimental teaching ways and methods.}

The new form of experimental teaching mode deriving from the connection between the multiple teaching ways and methods can effectively satisfy students'needs of personalized self-regulated study. For example, based on the cloud platform and big data laboratory, the associate professor Niu 
Haiyan in accounting college carries out the teaching methods of flipped classroom which is based on the cloud experimental teaching. Before class, students would be grouped by themselves and complete the experiment operation in dorm and study room, then they would participate in the discussion and research with questions. The teaching mode focusing on learners help teachers to reduce the duplication of effort and spend more energy and attention on the careful analysis of teaching. The multiple learning support, abundant learning content, flexible learning time and place can help students to bring their subjective initiative into play and exploit their potentialities.

Authentic learning is regarded as an important teaching strategy and is expected to promote the connection between students and the off-campus world and help students to make preparations to well adapt to the world off campus according to their on-campus experience. The university adopts the teaching method which combines the online and offline teaching to arouse students ' emotion and cognition and benefit both teaching and learning. Taking the simulation comprehensive training platform of enterprise operating management as an example, as for the online teaching, under the guidance of teachers, students can act several roles in different positions and experience the whole circle activity from the enterprise's establishment, operation, management to the participation in competition in the simulation commercial environment. As for the offline teaching, students can fully develop their individuality, interests, hobbies and fortes and design the content of the off-site practical training by themselves. For example, many optional projects including the poster design selection, the bidding of the optimal position where the posters are posted and the mock trial derive from the completion of the compulsory routine of completing the registration of establishing the enterprise. Students will transform from the legal marginal participants to the core members of learning community. Teachers would alternately use the heuristic and seminar teaching method and they become the observer, companion and assisstant of students' study.

\subsubsection{The connection between on-and off-campus resources.}

Various campus departments including experimental teaching center, academic affairs office, school league committee and career guidance center (college Business Park) unite in building the one-stop service platform for the entrepreneurship and innovation of college students. The experimental teaching center cooperates with the off-campus research institutions to test the students'interests of entrepreneurship and innovation, aptitude and ability level and describe the picture about the individual ability of entrepreneurship and innovation by the means of cloud computing and the integration of multisource data and the methods of invisible test and situation test. The data in ability picture is shared with various departments. Therefore, all the students selected and trained by the school league committee for the college students science \& technology innovation contest and the entrepreneurship cubation teams and projects absorbed and developed by the college business park can transcend the work paradigm judged by the past experience, make the education of innovation and entrepreneurship more accurate and help it shoot the arrow at the target.

The university cooperates with enterprises to build the laboratories and expand the employment of students. Building the laboratories by university and enterprise is a beneficial complement to the on-campus experimental teaching. It can not only extend the abundant teaching content but also help enterprises find the appropriate talents and further expand the employment of students. For example, the university cooperates with Goitsys Technology Co., Ltd to construct the laboratory about the outsourcing innovation of financial service, develop the course called Financial Comprehensive Business Experiment, compile the textbook for it and introduce the cutting-edge social practice application into the laboratory. On the teaching site, Goitsys is responsible for providing the real-time and high-frequency transaction data of the overseas stock exchange all around the world, appointing its trader as the teacher to instruct the spot transaction, providing a fixed number of simulated and real trading capital and training students as the trader of Euramerican stock exchange. For years there are more than 250 students who directly sign the employment agreement with the relevant financial institutions after the systematic training. 


\subsection{Three Integrations: Build the Integrated Experimental Teaching Mode.}

The integration of experiment, theory and practice promotes the extension from experimental teaching to the links theoretical teaching and extracurricular practice. Construct the intergrated simulative operating environment of campus business. Achieve the mutual nesting and integration between experimental teaching links and other links including theorectical class, extracurricular techonological innovation and social practice activity by adopting the methods of the teaching cases of micro experiment and economics and management experiment.

The integration of experiment, practical training and entrepreneurship can benefit both teaching and learning and connect professional education to the education of innovation and entrepreneurship. Students can become the subject of self-regulated study while they experience the real learning situation and teachers and students can interact with each other and grow up together by adopting the o2o online and offline coordinated methods to construct a progressive education teaching mode of innovation and entrepreneurship which combines the reinforcement of basic experiments, the stereotype in professional experiments, the integration of comprehensive experiments and the test of on-and off-campus training bases.

The integration of experiments, practice and scientific research promotes the positive interaction between teaching and scientific research. Encourage teachers to transform the questions and results in scientific research activities into the open experimental teaching projects to extend the abundant experimental teaching content. Break the resource barrier of of scientific research laboratories and teaching laboratories to share and combine the resources of software and data base and promote the cubation and cultivation of the scientific research subjects and results at high levels.

\section{Promote the Intelligent Experimental teaching based on internet, cloud computing, big data thinking and technology}

At present, the application of technology in teaching and learning is not the discussion and outlook of what kind of technology people will use. What it focuses on is to discuss practice and reflection of the way of using them. In the education information 2.0 era, it is necessary to pay more attention to exploring the teaching new modes based on information technology, developing the new educational service mode based on the internet and explore the new education governance mode in the information era. From digital education to intelligent education, the experimental teaching in economics and management is quickly intervening in the new educational ecological system which is constructed on the basis of the new generation of information technology including mobile internet and application, the internet of things, cloud computing and service and dig data analysis. The future smart laboratory will be an important situation in the intelligent university and an important site for students 'self-regulated learning. Therefore, the university prepares for a rainy day. It positively edges in the smart education filed characterized by the technology of cloud computing and big data and on the smart experimental teaching platform of Shandong University of Finance and Economics which is developed by the cooperation of universities, university and government, university and enterprise to explore the innovative way of the integrated development of teaching, learning, research, management and construction.

\subsection{Better teaching.}

Firstly, set the standard of collecting the data of experimental teaching knowledge points, construct the data sharing mechanism, break out of the information lonely island of laboratory and integrate and store various types of experimental teaching dara on campus to further organize and analyze the process and result data of students ' experiments and provide the personalized analysis for whether students comprehend and master the knowlege points or not. Finally apply the data analytic results to the question consulation and improvement at the levels of course design, course system optimization and speciality and realize the experimental teaching's feedback on theoretical teaching. 


\subsection{Better learning.}

In 2018, the 2.0 Action Plan for Educational Information released by the Ministry of Education of P.R.C demands that universities must strengthen the construction of the intelligent learning space of the intelligent laboratory, formulate the ubiquitous and intelligent learning system, promote the deep integration of information and intelligent technology and the whole process of the education and teaching. On the cloud experiment platform, the mass storage space provides possibility for the boundaryless and 24 - hours sharing mode without the dead end. The cloud experiment platform can make the remote access of mobile smart terminal come true and help students to gain the information of laboratory resources anywhere and anytime and arrange the learning pace and process by themselves to make students break through the limit of time and space, which provides the a synchronized and seamless environment of education teaching and experience sharing for the self-regulated and personalized learning of students at different levels.

\subsection{Better research.}

Break the barrier between scientific research laboratory and teaching laboratory by relying on the cloud experiment platform. Integrate the resources in 11 provincial key laboratories and 77 teaching laboratories including the Shandong dynamic simulation laboratory of economic operation, financial quantification and premium actuarial. Expand the scope of sharing the software and data base resources between scientific research laboratory and teaching laboratory. Make students fulfill their realistic scientific spirit that economics is an experimental science and intelligence is the daughter of experiment in the natural linking and transfer of teaching and scientific research on the basis of integrating the resources on the teaching and scientific research platforms.

\subsection{Better management.}

One of the important reflections of the integration of information technology, education and teaching is the prevalent application of information technology in teaching management for improving the management efficiency. Focusing on the problems of the distribution of laboratory resources in many campuses and the ever-growingsoftware upgrading requirements for hardware configuration, the experimental teaching center implement the intelligentmanagement through the cloud desktop management. Teachers and students can pass the identity authentication andaccess to their own desktop system by using the account number and passwords of their campus card anytime anywhere inthe network environment. Administrator can carry out the remote batch deployment, unified upgrade and patchinstallation for laboratory system to make the management maintenance more convenient. The experimental teachingresource management platform based on cloud technology realizes the integration and highly sharing of various teachingresources and information, provides students' open and self-regulated study with the good conditions, greatly reducesthe maintenance cost and improves the efficiency and level of the management of laboratory and experimental teaching.

\subsection{Better construction.}

The fisrt one is the cooperation between universities. The university positively takes part in the university alliance construction oriented by the resources sharing to build the interregional virtual simulation platform of sharing experimental teaching resources, which can promote the transformation from passive analysis to active reform in the data analytic application on the basis of effectively dealin with the diversity and large amount of education and teaching resources. The second one is the cooperation between university and government. The university cooperats with the Shandong Provincial Departemnt of Finance, Shandong Provincial Bureau of Satistics, Jinan Community Medical \& Healthcare Center to construct the new interdisciplinary research and innovation platforms including Shandong provincial big data center of finance, Shandong provincial monitoring laboratory of big data and macro economy, big data laboratory of intelligent health care, the laboratory of robot learning and financial data mining. The third one is the cooperation between university and enterprise. The university cooperates with the TP-LINK to construct the FSSC, 
strengthen the research and cooperation in the fields of finance sharing, acounting big data analysis, XBRL, internal control and government accounting and subversively reform the content of accounting courses. It also cooperates with Inspur to promote the cloud accouting teaching, which changes the traditional condition that the traditional financial softwares only can be operated in the fixed places including classroom and computer room and effectively promote students` self regulated learning.

\section{Conclusions}

The comprehensive reform of the integrated experimental teaching system helps it revitalize the resources, make it dynamic and explore more value space and development directions. Meanwhile, it creates the integration effect, multiplication effect, coordination effect and development effect in the process of its extension, integration and permeation in other education and teaching situation and promotes the effective cultivation of students'practical innovation ability and general ability to apply knowledge.

The integrated experimental teaching system treats experiments with other perspectives rather than the perspective of itself. It integrates and connects the experimental teaching contents and methods with resources, constructs the connected expeimental teaching mode which integrates experiment and theory with practice, the progressive expeimental teaching mode which integrates experiment, practical traning with entrepreneurship and the interactive expeimental teaching mode which integrates experiments, practice with scientific research. It also plays a distinctive role in educating people at the various levels of emotion, attitude, mastery of knowledge, scientific literacy and practical innovation ability and promote the deep sustainable development of experimental teaching in the major of economics and management.

Introduce the embedded micro experiment in economics and management and experimental teaching case method based on mobile internet, live up the class atmosphere and heightens student engagement in the learning process through the internet, cloud computing, big data thinking and technology. Realize the cloud experimental teaching; satisfy students'demand of applying the fragments of time to their self -study. Build the big data laboratory and the platform of scientific research innovation through the cooperation between university and other parties including university, government and enterprise. Attempt to mine and analyze the teaching data by accumulating the data of processes, conditions and results of experimental teaching in order to provide corrective suggestions for the theoretical course design and specialty construction.

\section{Acknowledgements}

This work was financially supported by the University Teaching Reform Research Project of Shandong Province (Grant No:Z2016Z035)

\section{References}

[1] Zhigang Liu, Research \& Exploration in Laboratory, Vol.28 (2009), p. 2, In Chinese.

[2] Jinhong Hu, Hongfei Li and Tao Huang, Research \& Exploration in Laboratory, Vol.34 (2015), p.141, In Chinese .

[3] Le Gong, Shuo Chen, China Adult Education, Vol.17 (2017), p. 24, In Chinese.

[4] Jin Zhao, Jianjun Zhang and Wang Yijun, e-Education Research, Vol.39 (2018), p.22, In Chinese.

[5] Enquan Yao, Zuokui Li. Education Science, Vol.25 (2009), p.49, In Chinese.

[6] Bangqi Liu, Wisdom Education: education reform and transformation in the new era, China Education Daily 2018-01-27(3)

[7] Johnson,L., Liu,D., Huang,R., Adams Becker,S.,Gao,Y, Cummins,M., Davis,A.,and Estrada, 
V.(2016).2016 NMC Technology Outlook for Chinese K12 Education: A Horizon Project Regional Report. Austin, Texas: The New Media Consortium.

[8] Hongliang Yu, Yajun Zhang,Chongqing Higher Education Research, Vol.5 (2017), p.8, In Chinese.

[9] Chaozi Lei, Journal of East China Normal University, Vol.36 (2018), p.17, In Chinese.

[10] Xiaoliu Zhong, Shuqiang Song, and Min Hu, etc. , Journal of Distance Education, Vol.33 (2015), p.35, In Chinese.

[11] Zongkai Yang, HaoYang and Di Wu, Educational Research, Vol.35 (2014), p.89, In Chinese. 